\title{
Level of anxiety, depression, self-esteem and quality of life among the women with vaginitis
}

\author{
Gulsum Uysal $^{1 *}$, Sefa Arlıer¹, Fulya Cagli², Hatice Akkaya ${ }^{3}$, Murat Soyak ${ }^{4}$, Basak Cıngılıoglu², \\ Emre Destegul ${ }^{2}$, Gokhan Acmaz
}

\begin{abstract}
${ }^{1}$ Department of Obstetrics and Gynecology, Adana City Education and Research Hospital, Adana, Turkey ${ }^{2}$ Department of Obstetrics and Gynecology, Kayseri Education and Research Hospital, Kayseri, Turkey ${ }^{3}$ Department of Obstetrics and Gynecology, Zekai Tahir Burak Women's Health Education and Research Hospital, Ankara, Turkey

${ }^{4}$ Department of Psychiatry, Kayseri Education and Research Hospital, Kayseri, Turkey

${ }^{5}$ Department of Obstetrics and Gynecology, Erciyes University School of Medicine, Kayseri, Turkey
\end{abstract}

Received: 17 May 2018

Accepted: 23 June 2018

*Correspondence:

Dr. Gulsum Uysal,

E-mail: gulsumaykut@yahoo.com

Copyright: (c) the author(s), publisher and licensee Medip Academy. This is an open-access article distributed under the terms of the Creative Commons Attribution Non-Commercial License, which permits unrestricted non-commercial use, distribution, and reproduction in any medium, provided the original work is properly cited.

\begin{abstract}
Background: Present aim is to evaluate anxiety, depression, quality of life and self-esteem in patients with vaginitis (not only specific to candidasis) and also to determine factors affecting vaginitis such as demographic, cultural and psychological causes.

Methods: Each patient completed a self-administered questionnaire (Rosenberg' Self-Esteem Scale, Short-Form 36, Quality of Life Scale, Beck Anxiety Inventory, and Beck Depression Inventory, Body Image Scale) and underwent a careful examination of the vulva and vagina. The cross-sectional study was carried out with two groups. The first group consisted of 107 women between the ages 18 and 45 years and had no physical disease but reccurrent vulvovaginitis ( $\geq 4$ in a year). The comparison control group consisted of 94 healthy (no vaginitis symptoms in 12 months) age matched volunteer participants.

Results: Women with vaginitis had significantly higher anxiety and depression scores. There was no statistically significant difference in body image scale. Regarding type of marriage, arranged type was statistically significantly higher in vaginitis group while flirting type was statistically higher in control group. University school degree and income was statistically significantly lower in vaginitis group. Living residence as rent and vaginal douch was statistically significantly higher in vaginitis group.

Conclusions: A better detailed history should be taken into consideration for personal stress sources and treatment support should be provided for patients with vaginitis. Not only gynecologists but also a multidisciplinary team should take part in the treatment and follow up of the patients to cope with recurrency even in non-specific vaginitis.
\end{abstract}

Keywords: Anxiety, Body image scale, Depression, Rosenberg' self-esteem scale, Short-form 36, Vaginitis

\section{INTRODUCTION}

Vaginitis is a general term of inflammation of the vaginal wall usually caused by yeast infections, bacterial vaginosis and trichomoniasis. ${ }^{1}$ Vulvovaginal itching, irritation, pain and noticeable changes in vaginal discharge are also diagnosed as vaginitis. ${ }^{2}$ Some predisposing factors are pregnancy, oral contaceptives, activity deficiency, high intake of sugar, diabetes mellitus, oral sex and vaginal douching.,4 Vaginal discharge is a very common problem and vaginitis is the 
most prevalent infection of low genital track. ${ }^{1,2}$ This infection alone is accounted for $>10 \%$ of outpatient clinics especially in women of reproductive age. ${ }^{3}$ Moreover, it is also an important public health problem affecting men, families and communities. ${ }^{1}$

It was shown that patients with recurrent vaginal candidiasis (RVVC) were significantly vulnerable to clinical depression and less satisfied with life and had poorer self-esteem. ${ }^{5}$ Therefore, patients with vaginal candidiasis had problems with their sexual and emotional relationships. ${ }^{5}$ Ehrström et al. also evaluated the association between recurrent vulvovaginal candida and chronic stress. ${ }^{6}$ They examined morning rise of salivary cortisol level to indicate signs of chronic stress. The results of their study showed that chronic stress may play a role in the pathogenesis of RVVC. ${ }^{6}$

Our aim is to evaluate anxiety, depression, quality of life and self-esteem in patients with vaginitis (not only specific to candidasis) and also to determine factors affecting vaginitis such as demographic, cultural and psychological causes.

\section{METHODS}

This study was conducted at Kayseri Education and Research Hospital of Medicine between years of 20152016. The study was approved by the Ethical Committee of University Hospital, and written informed consent was obtained from all the participants.

The cross sectional study was carried out with two groups. The first group consisted of 107 women between the ages 18 and 45 years and had no physical disease but reccurrent vulvovaginitis ( $\geq 4$ in a year). The comparision control group consisted of 94 healthy (no vaginitis symptoms in 12 months) age matched volunteer participants. Those who had chronic diseases, had other gynecological complaints such as abnormal bleeding etc., positive malignancy, psychotic disorders and used antidepressants and mood stabilizers (Li, Valproic acid, etc.) were excluded from the study. Hysterectomized, pregnant, those who reported receiving antibiotics, corticosteroids or immunsupressive drugs were also excluded. All participants had at least primary school degree.

Each patient completed a self administered questionarie and all women underwent a careful examination of the vulva and vagina. Widely used, reliable and valid clinical psychological health rating scales were used in this study followed below:

- $\quad$ Rosenberg' Self-Esteem Scale (RSES),

- Short-Form 36 (SF- 36) Quality of Life Scale,

- Beck Anxiety Inventory (BAI), and

- Beck Depression Inventory (BDI),

- $\quad$ Body Image Scale (BIS).
These scales and inventories were used and scored by the same psychiatrist. The basic questionarie form consisted of sociodemographic characteristics such as age, educational level, income status, marital status, type of marriage, living residence, profession, and number of children. Vaginal douch habit and body mass index (BMI) were also asked and recorded.

SF-36 Quality of Life Scale is the most widely used scale in order to measure the quality of life. The scale was designed by Rand Corporation in 1992 and validity and reliability tests of the Turkish version were performed by Kocyigit et al. ${ }^{7,8}$

Rosenberg' Self-Esteem Scale (RSES) is a Likert-type self-rated scale composed of 10 questions and was designed by Rosenberg. ${ }^{9}$ Validity and reliability tests of the Turkish form were performed by Cuhadaroglu. ${ }^{10}$ The first ten items of the scale are used to evaluate selfesteem. A total score between 0 and 1 indicates high level of self-esteem, a total score between 2 and 4 indicates moderate level of self-esteem and a total score between 5 and 6 points out low level of selfesteem. ${ }^{10}$

Beck Depression Inventory (BDI) was developed by Beck et al. and measures physical, emotional, and mental symptoms in depression. ${ }^{11}$ It is self-rated inventory with 21-symptom category. Higher total scores indicate higher severity of depression. Validity and reliability tests of the Turkish version were performed by Hisli. ${ }^{12}$

Beck Anxiety Inventory (BAI) is a self-rated inventory used to determine the frequency of anxiety symptoms. It is composed of 21 items and is a Likert-type inventory rated from 0 to 3 . Higher total scores indicate higher severity of anxiety. ${ }^{13}$ Validity and reliability tests of the Turkish version were performed by Ulusoy. ${ }^{14}$

Body Image Scale (BIS) was developed by Secord and Jourand in 1953 and validated and credited by Hovardaoğlu in $1989 . .^{15,16}$ The scale contains 40 items, each of which relates to an organ or part of the body (arm, leg, face, etc.) or a function (such as sexual activity level). The cut score of the scale was 135 , and those with a pawn below 135 were defined as having a low perception of body image.

\section{Statistical analysis}

The analysis of the data was performed with SPSS 18 software. Shapiro-Wilk test was used in order to determine whether or not the data followed a normal distribution. The data were presented as frequency and percentages, means \pm SD or median (25th and 75th). For the qualitative data, chi-square analysis was performed for intergroup comparisons while for the quantitative data oneway variance analysis. For all analyses, statistical significance was defined by a probability level of $P$ $<0.05$. 


\section{RESULTS}

The main characteristics of the study groups were described in Table 1. No significant difference was found between age, marital status, body mass index (BMI) and number of children and number of coitus (weekly). Regarding type of marriage, arranged type was statistically significantly higher in vaginitis group while flirting type was statistically higher in control group. University school degree and income was statistically significantly lower in vaginitis group. Living residence as rent and vaginal douch was statistically significantly higher in vaginitis group.

Table 1: Basic characteristics of study and control groups.

\begin{tabular}{|c|c|c|c|}
\hline & $\begin{array}{l}\text { Group1 } \\
\text { (vaginitis) }\end{array}$ & $\begin{array}{l}\text { Group } 2 \\
\text { (healthy } \\
\text { controls) }\end{array}$ & p \\
\hline Age & $33.7 \pm 6.0$ & $34.6 \pm 5.4$ & 0.20 \\
\hline \multicolumn{4}{|l|}{ Marital status } \\
\hline Married & $103(96.3 \%)$ & $91(96.8 \%)$ & \multirow{3}{*}{0.88} \\
\hline Divorced & $2(1.9 \%)$ & $2(2.1 \%)$ & \\
\hline Widow & $2(1.9 \%)$ & $1(1.1 \%)$ & \\
\hline \multicolumn{4}{|l|}{ Type of marriage } \\
\hline Arranged & $71(66.4 \%)$ & $36(38.3 \%)$ & \multirow{2}{*}{$<0.01$} \\
\hline Flirting & $36(33.6 \%)$ & $58(61.7 \%)$ & \\
\hline \multicolumn{4}{|l|}{ Education } \\
\hline Primary school & $59(55.1 \%)$ & $8(8.5 \%)$ & \multirow{3}{*}{$<0.01$} \\
\hline High school & $39(36.4 \%)$ & $29(30.9 \%)$ & \\
\hline University & $9(8.4 \%)$ & $57(60.6 \%)$ & \\
\hline $\mathrm{BMI}\left(\mathrm{kg} / \mathrm{m}^{2}\right)$ & $26.5 \pm 4.8$ & $25.8 \pm 4.0$ & 0.30 \\
\hline \multicolumn{4}{|l|}{ Living residence } \\
\hline Rent & $56(52.3 \%)$ & $32(34 \%)$ & \multirow{2}{*}{$<0.01$} \\
\hline Lanlord & $50(46.7 \%)$ & $62(66 \%)$ & \\
\hline $\begin{array}{l}\text { Number of } \\
\text { children }\end{array}$ & $2(0-6)$ & $2(0-5)$ & 0.33 \\
\hline Income $(\mathrm{tl})^{*}$ & $\begin{array}{l}1200 \\
(0-5000)\end{array}$ & $\begin{array}{l}2500 \\
(900-10000)\end{array}$ & $<0.01$ \\
\hline $\begin{array}{l}\text { Vaginal douch } \\
\text { yes/no }\end{array}$ & $57 / 50$ & $19 / 75$ & $<0.01$ \\
\hline $\begin{array}{l}\text { Number of } \\
\text { Coitus (weekly) }\end{array}$ & $3(0-4)$ & $2(0-4)$ & 0.17 \\
\hline
\end{tabular}

BMI: Body Mass Index tl: turkish liras *values expressed as median (minimum -maximum)

Women with vaginitis had significantly higher anxiety scores. Table 2 included anxiety and avoidance scores of BDI, BAI, and BIS. All SF-36 domains were lower in vaginitis group. The domains related to physical functioning (PF), physical role function (PRF), pain, general health $(\mathrm{GH})$, vitality, social functioning (SF), emotional role function (ERF), and emotional well-being (EWB) were also showed in Table 2. Although there were statistically significant differences in all of these parameters, there were no statistically significant difference in body image scale (BIS) compared to the healthy group.
Table 2: Evaluation of BDI, BAI, BIS and SF -36 scale among groups.

\begin{tabular}{|llll|}
\hline & $\begin{array}{l}\text { Group 1 } \\
\text { (vaginitis) }\end{array}$ & $\begin{array}{l}\text { Group 2 } \\
\text { (healthy } \\
\text { controls) }\end{array}$ & P \\
\hline BDI & $14.5(1-48)$ & $10(0-41)$ & $<0.01$ \\
\hline BAI & $17(1-53)$ & $10(0-48)$ & $<0.01$ \\
\hline BIS & & & \\
\hline$>135$ & $7(6.5 \%)$ & $7(7.4 \%)$ & 0.91 \\
\hline$<135$ & $100(93.5 \%)$ & $87(92.6 \%)$ & \\
\hline PF & $75.5 \pm 7.4$ & $81.1 \pm 7.4$ & $<0.01$ \\
\hline PRF & $78.9 \pm 7.4$ & $81.6 \pm 11.2$ & $<0.01$ \\
\hline Pain & $78.6 \pm 12.2$ & $83.2 \pm 7.0$ & $<0.01$ \\
\hline GH & $71.1 \pm 5.6$ & $73.9 \pm 4.3$ & $<0.01$ \\
\hline Vitality & $65.8 \pm 5.9$ & $70.0 \pm 5.3$ & $<0.01$ \\
\hline SF & $85.3 \pm 9.7$ & $88.3 \pm 5.8$ & $<0.01$ \\
\hline ERF & $85.2 \pm 6.2$ & $88.7 \pm 4.8$ & $<0.01$ \\
\hline EWB & $69.6 \pm 6.1$ & $73.8 \pm 4.4$ & $<0.01$ \\
\hline
\end{tabular}

BDI: Beck Depression Inventory, BAI: Beck Anxiety Inventory, BIS: Body Image Scale Data related to Short Form 36 Quality of life scale: SF-36 PF: physical functioning; PRF: physical role function; GH: general health; SF: social functioning; ERF: emotional role function and EWB: emotional well-being.

Table 3 included the data related to self-esteem (SE), continuity in self-concepts (CSC), trust in people (TIP), sensitiveness to criticism (SC), depressive affect (DA), day dreaming (DD), psychosomatic symptoms (PSS), feeling threat in interpersonal relations (FTIR), intensity of discussion (ID), parental interest (PI), father-relation (FR), and psychic isolation (PsI). Except TIP, PI and PsI, all parts of Rosenberg self-esteem scale were significantly different between groups.

\section{DISCUSSION}

The result of this study indicated that women with recurrent vaginitis show more signs of stress, depression and anxiety and low quality of life compared with healthy, age matched control subjects. The lower income and lower education level accompanying with arranged type of marriage were significantly higher in vaginitis group. This is the first published study evaluating social causes and impacts leading to vaginitis and specifically examining self-esteem, anxiety, depression levels and quality of life of women with nonspecific recurrent vaginitis.

In a study, they revealed higher degree of perceived stress in women with RVVC compared with healthy controls and mentioned that lifestyle factors and chronic stress may contribute to the development of RVVC. ${ }^{17}$ Moreover, women with RVVC had more lifestyle related stress symptoms including long term stress, work-related stress and burnout. ${ }^{17}$ 
Table 3: Evaluation of Rosenberg self-esteem scale among groups.

\begin{tabular}{|c|c|c|c|}
\hline & $\begin{array}{l}\text { Group1 } \\
\text { (vaginitis) }\end{array}$ & $\begin{array}{l}\text { Group } 2 \\
\text { (healthy controls) }\end{array}$ & $\mathbf{P}$ \\
\hline \multicolumn{4}{|c|}{ Self-esteem } \\
\hline Low & 11 & 1 & \multirow{3}{*}{$<0.01$} \\
\hline Medium & 55 & 22 & \\
\hline High & 41 & 71 & \\
\hline \multicolumn{4}{|l|}{$\mathrm{CSC}$} \\
\hline Low & 6 & 0 & \multirow{3}{*}{$<0.01$} \\
\hline Medium & 86 & 62 & \\
\hline High & 15 & 32 & \\
\hline \multicolumn{4}{|l|}{ TIP } \\
\hline Low & 0 & 2 & \multirow{3}{*}{0.15} \\
\hline Medium & 55 & 55 & \\
\hline High & 52 & 37 & \\
\hline \multicolumn{4}{|l|}{$\mathrm{SC}$} \\
\hline Low & 0 & 0 & \multirow{3}{*}{$<0.01$} \\
\hline Medium & 95 & 61 & \\
\hline High & 12 & 33 & \\
\hline \multicolumn{4}{|l|}{$\mathrm{DA}$} \\
\hline Low & 7 & 3 & \multirow{3}{*}{0.04} \\
\hline Medium & 71 & 50 & \\
\hline High & 29 & 41 & \\
\hline \multicolumn{4}{|l|}{ DD } \\
\hline Low & 0 & 0 & \multirow{3}{*}{$<0.01$} \\
\hline Medium & 32 & 47 & \\
\hline High & 75 & 47 & \\
\hline \multicolumn{4}{|l|}{ PSS } \\
\hline Low & 42 & 13 & \multirow{3}{*}{$<0.01$} \\
\hline Medium & 51 & 54 & \\
\hline High & 14 & 27 & \\
\hline \multicolumn{4}{|l|}{ FTIR } \\
\hline Low & 0 & 0 & \multirow{3}{*}{$<0.01$} \\
\hline Medium & 77 & 44 & \\
\hline High & 30 & 50 & \\
\hline \multicolumn{4}{|l|}{ ID } \\
\hline Low & 0 & 0 & \multirow{3}{*}{0.04} \\
\hline Medium & 11 & 19 & \\
\hline High & 96 & 75 & \\
\hline \multicolumn{4}{|l|}{ PI } \\
\hline Low & 13 & 8 & \multirow{3}{*}{0.4} \\
\hline Medium & 51 & 40 & \\
\hline High & 43 & 46 & \\
\hline \multicolumn{4}{|l|}{ FR } \\
\hline Low & 5 & 27 & \multirow{3}{*}{$<0.01$} \\
\hline Medium & 43 & 43 & \\
\hline High & 59 & 24 & \\
\hline \multicolumn{4}{|l|}{ PsI } \\
\hline Low & 0 & 0 & \\
\hline Medium & 38 & 36 & 0.6 \\
\hline High & 69 & 58 & \\
\hline
\end{tabular}

Data related to Rosenberg' Self Esteem Scale: SE: self-esteem; CSC: continuity in self-concepts; TIP: trust in people; SC:sensitiveness to criticism; DA:depressive affect; DD: daydreaming; PSS: psychosomatic symptoms; FTIR: feeling threat in interpersonal relations; ID: intensity of discussion; PI: parental interest; FR: father-relation and PsI: psychic isolation
Meyer et al. concluded that psychosocial factors, particularly stress, were the primary causes of Candida albicans vulvovaginitis. ${ }^{18}$ They also said that traditional antimycotic treatment influences only the symptoms of the illness, not its causes, and had no effect on the probability of a relapse. ${ }^{18}$ Besides treatment of vaginitis, stress should be coped with for recurrence. As expected, significant differences were seen between patients and controls regarding vaginal douch habit. Vaginitis is more frequent in the patients with this habit because the vaginal douch breaks the vaginal flora and makes vagina more vulnerable to infection and inflammation. ${ }^{5}$ Although discomfort of having repeated vaginitis, which also may have a negative influence on the sexual relationship, there were no differences in the number of weekly intercourse between patients and control subjects. Arranged marriage was also higher in vaginitis group. This result may be explained with the culture of the population.

Due to personal habits lower education may affect vaginal flora and this may be an additive factor for vaginitis. On the other hand, lower income in itself was a risk for anxiety and vaginitis. According to this study inventories including psychosomatic symptoms (PSS) and depressive affect (DA), the anxiety and depression level were higher in patients with vaginitis. In fact, the anxiety or depression affecting the entire body makes vagina susceptible for infections like low human immunity. Moreover, chronic stress has been shown to be an effect on the immune system. ${ }^{18}$ The signs of chronic stress in vaginitis and treatment responses related to stress were also evaluated. ${ }^{6,19}$ Eström et al. showed morning rise of salivary cortisol level which was related to long-term perceived stress. ${ }^{6}$ They thought that the stress factor might contribute to a reactivation of candida vulvovaginitis, which was similar with the accepted association between stress and reactivation of herpes genitalis. ${ }^{6}$ This stress may be an additive index to level of anxiety and depression.

Zhu et al showed that the mean SF-36 dimension scores for physical function, role physical, bodily pain, general health, vitality, social functioning, role emotional, and mental health were significantly lower in the patients with RVVC than in the controls. ${ }^{20}$ They also mentioned that the mental health domains were the most affected. Similarly, in another study, subjective health status and quality of life during and in between acute inflammatory episodes in women with RVVC were significantly worse than in the general population, despite the use of antifungal therapy. ${ }^{21} 68 \%$ of the participants reported depression/anxiety problems during acute episodes and $54 \%$ reported depression/anxiety when they were not experiencing episodes, compared with less than $20 \%$ for the general population. ${ }^{21}$

Current study results were consistent with Zhu and Aballea et al confirmed lower physical, social functioning and emotional well-being not only in candidasis but also in nonspecific vaginitis. ${ }^{20,21}$ Vaginitis was found to be 
affected by stress factors, but it may also be related to education and income level which in turn may trigger stress, which may be caused by vaginitis. Study had several limitations. Firstly, the vaginal discharges were not cultured. Secondly, the small sample sizes of participants. Larger numbers would be desirable for detection of particular differences in ethnicity which may influence womens' psychological perspectives and strategies or willingness to answer the questionnaire. We think that this is the first published data investigating the multifactorial aetiology of non-specific vaginitis in women in a developing country. Anxiety, depression, self-esteem and quality of life among the women with vaginitis should be examined entirely. We suggest that not only gynecologists but also a multidisciplinary team should take part in the treatment and follow up of the patients to cope with recurrence even in nonspecific vaginitis.

\section{CONCLUSION}

In conclusion, a better detailed history should be taken into consideration for personal stress sources and treatment support should be provided for patients with vaginitis.

\section{ACKNOWLEDGMENTS}

The authors thank Onur Kadir Uysal for his contribution to this research.

\section{Funding: No funding sources}

Conflict of interest: None declared

Ethical approval: The study was approved by the Ethical Committee of University Hospital (2014/342)

\section{REFERENCES}

1. Parsapour R, Majlessi F, Rahimiforoushani A, Sadeghi R. Determination of factors affecting relapse of vaginitis among reproductive-aged women: An experimental study. Electron Phys. 2017;9:3499-507.

2. Patel V, Pednekar S, Weiss H, Rodrigues M, Barros P, Nayak B et al. Why do women complain of vaginal discharge? A population survey of infectious and pyschosocial risk factors in a South Asian community. Int J Epidemiol. 2005;34: 853-62.

3. Karaer A, Boylu M, Avsar AF. Vaginitis in Turkish Women: Symptoms, Epidemiologic - Microbiologic Association. Eur J Obstet Gynecol Reprod Biol. 2005;1:211-5.

4. Farage MA, Miller KW, Ledger WJ. Determining the Cause of Vulvovaginal Symptoms. Obstet Gynecol Surv. 2008;63:445-64.

5. Irving G, Miller D, Robinson A, Reynolds S, Copas AJ. Psychological factors associated with recurrent vaginal candidiasis: a preliminary study. Sex Transm Inf 1998;74:334-8.
6. Ehrström SM, Kornfeld D, Thuresson J, Rylander E. Signs of chronic stress in women with recurrent candida vulvovaginitis. Am J Obstet Gynecol. 2005;193:137681.

7. Ware JE Jr, Sherbourne CD. The MOS 36-item shortform health survey (SF-36). I. Conceptual framework and item selection. Med Care. 1992;30:473-83.

8. Koçyiğit H, Aydemir Ö, Fişek G, Ölmez N, Memiş AK.

9. Reliability and validity of the Turkish version of Short Form-36 (KF-36). Drug Treatment J. 1999;12:102-6.

10. Rosenberg M. Society and the Adolescent Self-Image, Princeton University Press, Princeton, New Jersey, USA;1965.

11. Cuhadaroglu F. Self-esteem among adolescents. Hacettepe University, Ankara, Turkey;1986.

12. Beck AT, Ward CH, Mendelsohn M, Mock J, and Erbaugh J. An inventory for measuring depression. Arch General Psychiatry. 1961;4:561-71.

13. Hisli N. A study on validity and reliability tests of Beck depression inventory. Psychol J. 1988;6:118-122.

14. Beck AT, Epstein N, Brown G, and Steer RA. An inventory for measuring clinical anxiety: psychometric properties. J Consulting Clin Psychol. 1988;56:893-7.

15. Ulusoy M. Beck anxiety inventory (BAI): validity and reliability tests. Bakirkoy Mental Diseases Hospital, Istanbul, Turkey;1993.

16. Secord PF, Jourard SM. The appraisal of body-cathexis: Body-cathexis and the self. J Consult Psychol. 1953;17:343-7.

17. Hovardaoğlu S, Özdemir YD. The reliability and validity study of the Perception of the Body Sense / Satisfaction levels of body image of schizophrenic and major depressed patients. Graduate thesis, Gazi University Institute of Social Sciences, Ankara;1990.

18. Ehrström S, Kornfeld D, Rylander E. Perceived stress in women with recurrent vulvovaginal candidiasis. J Psychosom Obstet Gynaecol. 2007;28:169-76.

19. McEwen BS. Protective and damaging effects of stress mediators. N Engl J Med. 1998;238:171-9.

20. Meyer H, Goettlicher S, Mendling W. Stress as a cause of chronic recurrent vulvovaginal candidosis and the effectiveness of the conventional antimycotic therapy. Mycoses. 2006;49:202-9.

21. Zhu YX, Li T, Fan SR, Liu XP, Liang YH, Liu P. Health-related quality of life as measured with the Short-Form 36 (SF-36) questionnaire in patients with recurrent vulvovaginal candidiasis. Health Qual Life Outcomes. 2016 Apr 29;14:65.

22. Aballéa S, Guelfucci F, Wagner J, Khemiri A, Dietz JP, Sobel J, et al. Subjective health status and health-related quality of life among women with recurrent vulvovaginal candidosis (RVVC) in Europe and the USA. Health Qual Life Outcomes. 2013;11:169.

Cite this article as: Uysal G, Arlier S, Cagli F, Akkaya H, Soyak M, Cingilloglu B. Level of anxiety, depression, self-esteem and quality of life among the women with vaginitis. Int J Reprod Contracept Obstet Gynecol 2018;7:3009-13. 